\title{
Embolization of High-Flow Renal Arteriovenous Fistula
}

Dear Editor,

Endovascular embolization of aneurysmal-type renal arteriovenous malformation has inherent risk of migration of the embolic agents to the pulmonary arteries.

We report a case of a 49-year-old male who presented with hypertension and high-flow renal arteriovenous fistula (AVF) with dilated venous sac [Figure 1].

Using a coaxial technique, a $4 \mathrm{~mm} \times 11 \mathrm{~mm}$ Sceptor $\mathrm{XC}$ (Microvention) was advanced into the renal AVF. Despite maximal inflation of the balloon, which reached
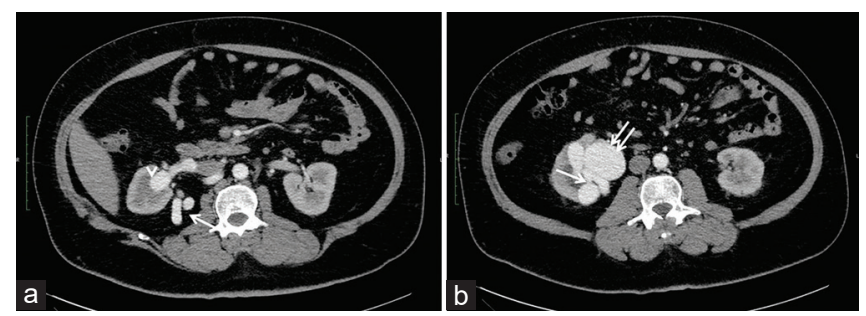

Figure 1: (a) Computed tomography angiography at the level of right renal hilum showing renal artery (arrow) and early filling of the venous sac (arrowhead). (b) Computed tomography angiography (arterial phase) just below the level of computed tomography angiography of (a) showing multiple dilated veins and a large aneurysmal venous sac (double arrows). The fistulous communication is visualized (arrow)
$6 \mathrm{~mm}$, flow reduction was insufficient to prevent coil migration through the fistulous communication.

A 6 Fr balloon guide catheter (Cello, EV3) was used to slow flow through the shunt followed by a combination of n-BCA glue and coil embolization using Apollo microcatheter with detachable tip (Medtronic). A $2 \mathrm{ml}$ of $90 \% \mathrm{n}$-BCA (2 ml histocryl mixed with $2 \mathrm{~mL}$ of lipiodol) [Figure 2]. Then, 0.035 -inch $15 \mathrm{~mm} \times 40 \mathrm{~cm}$ and $8 \mathrm{~mm} \times 40 \mathrm{~cm}$ interlock fibered coils (Boston Scientific) were deployed in the feeding artery. This was followed by injection of $2 \mathrm{ml}$ of $25 \%$ precipitating hydrophobic injectable liquid embolic (Microvention), resulting in completion occlusion of the fistula. The patient recovered from the procedure with resolution of the hypertension [Figure 3].

The main complications of embolization of renal AVF include pulmonary embolism due to coil migration or thrombus from the aneurysmal venous sac thrombosis, renal vein thrombosis or inadvertent occlusion of the renal artery branches, and possible development of postembolization syndrome or renal dysfunction.

\section{Financial support and sponsorship}

Nil.
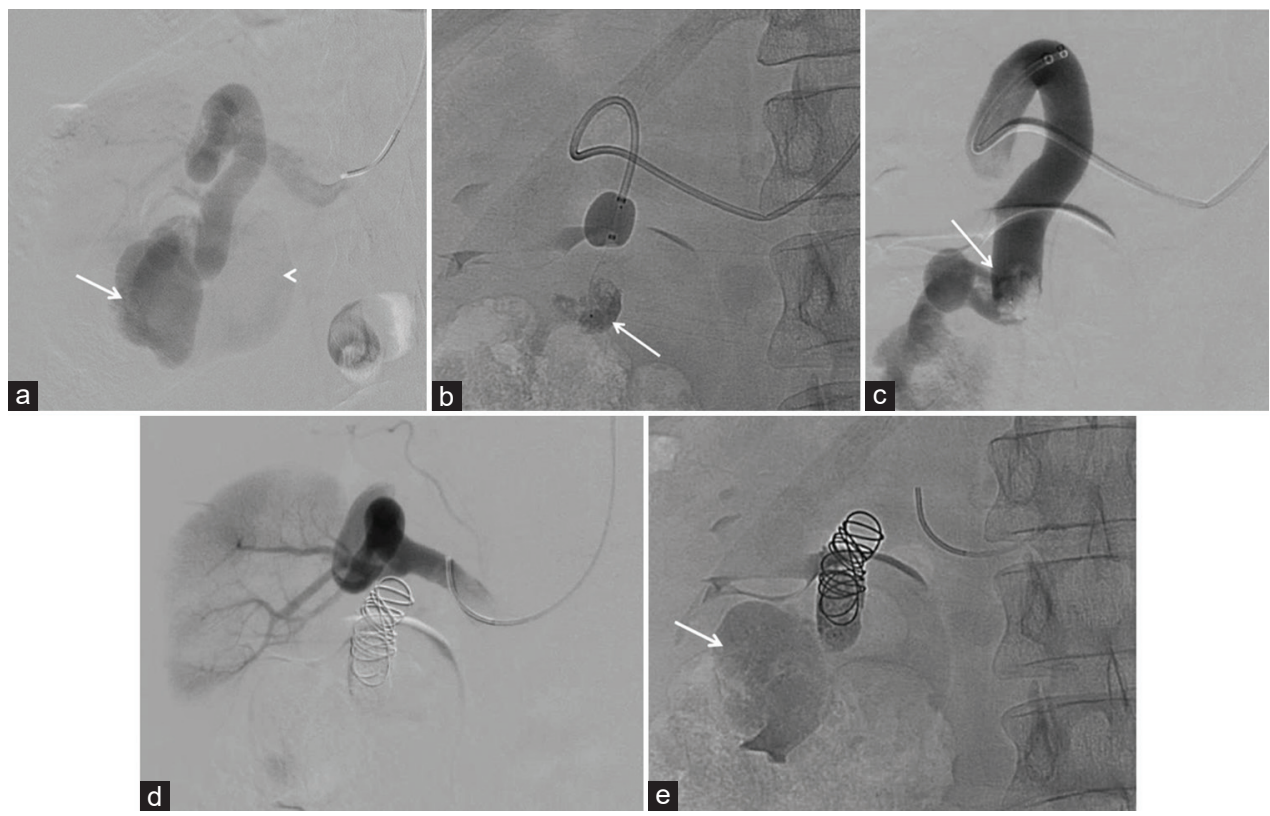

Figure 2: (a) Right renal arteriogram from the left brachial artery using a 5 Fr C2 cobra catheter with manual injection of 8 cc of $50 \%$ diluted contrast. It shows the dilated feeding artery, a direct communication between the segmental feeding artery and venous sac (arrow), and faint filling of an aneurysmal venous sac. The renal parenchyma is poorly seen due to the high-flow arteriovenous fistula. (b) After placement of a 6 Fr occlusion balloon catheter (6 Fr Cello, Medtronic) in the feeding artery, $2 \mathrm{~mL}$ of $95 \% \mathrm{n}-\mathrm{BCA}$ (arrow) was injected via a microcatheter. (c) After deflation of the balloon following an injection of glue in the feeding artery, renal digital subtraction angiography showinf sluggish blood flow around the n-BCA cast (arrow). (d) After embolization of the feeding artery with two 0.035 -inch interlock coils and precipitating hydrophobic injectable liquid into the coils interstices, completion renal angiogram showing occlusion of the feeding artery and good filling of the upper and mid poles of the kidney. The lower pole of the kidney is supplied by an accessory renal artery (not shown). (e) Nonsubtracted image post embolization showed the precipitating hydrophobic injectable liquid embolization material into the interstices of the coil mass as well as stasis of contrast in the aneurysmal sac (arrow) of the draining vein 

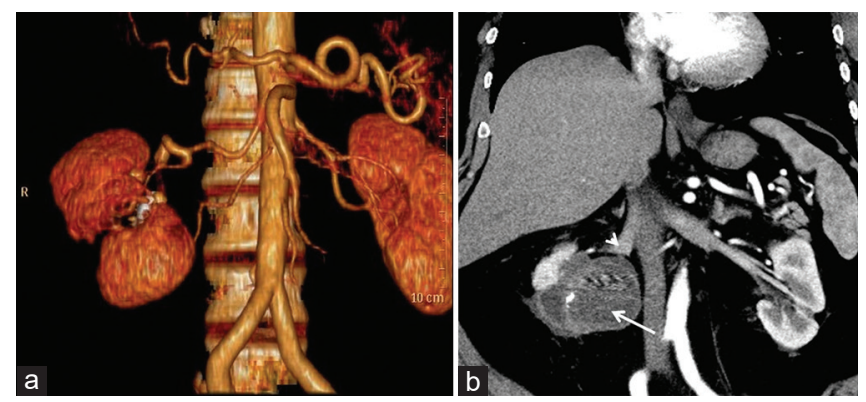

Figure 3: (a) volume rendering images for patient after 3 months showing a total occlusion of arteriovenous fistula. The lack of blood flow to the mid-pole of the kidney is due to the previous embolization of the arteriovenous fistula. Blood flow to the upper and lower poles are preserved. (b) Coronal image in the arterial phase of renal computed tomographic angiography showing opacification of the right renal vein (arrowhead) and thrombosed venous sac (arrow)

\section{Conflicts of interest}

There are no conflicts of interest.

\section{Omar J. AlThaqufi, Abdullah Mohammed Almughir, Fadhel Mohsen Almolani}

Department of Interventional Radiology, King Fahad Specialist Hospital, Dammam, Saudi Arabia
Address for correspondence: Dr. Omar AlThaqufi, 8951 2A, Firdaws District, Unit No. 4, Dammam 34251-5052, Saudi Arabia.

E-mail: omaralthaqufi@otmail.com

Received: 02-01-2020

Revised: $13-03-2020$

Accepted: $15-05-2020$

Online Published: $10-08-2020$

This is an open access journal, and articles are distributed under the terms of the Creative Commons Attribution-NonCommercial-ShareAlike 4.0 License, which allows others to remix, tweak, and build upon the work non-commercially, as long as appropriate credit is given and the new creations are licensed under the identical terms.

\begin{tabular}{|l|l|}
\multicolumn{2}{c|}{ Access this article online } \\
\hline Quick Response Code: & Website: \\
& www.arabjir.com \\
\cline { 2 - 2 } & DOI: \\
\hline
\end{tabular}

How to cite this article: AlThaqufi OJ, Almughir AM, Almolani FM. Embolization of high-flow renal arteriovenous fistula. Arab $\mathrm{J}$ Intervent Radiol 2020;4:134-5. 